which, further, should be provided with all that is necessary for the establishment of the stations, the safety and the subsistence of the observers, should not leave those regions before bringing the mission to Tahiti, where our envoyés would find means of transport for their return, either by the way they went, or (which would seem preferable), by way of Australia.

\section{THE TRANSIT OF VENUS ON WEDNESDAY,} DECEMBER 6

$A \mathrm{~T}$ the Transit of Venus in 1874 the tables of the A planet prepared by Prof. Hill appeared to have a decided advantage over those of Leverrier. The correction to the tabular place deduced from the observations of the transit is in close accordance with that shown by a meridian observation at Washington on the day preceding the phenomenon. Although the entire discordance was not regatived by the tables of Prof. Hill, they went far towards removing it in 1874, and as the coming transit (December 6) will take place in nearly the same point in the planet's orbit, we shall assume in what follows, that the tables of the American astronomer will again be fairly correct. Prof. Newcomb assumes and probably $n$ ith much reason, that the error of Leverrier's tables will prove to be an increasing one, and is therefore inclined to apply a still larger correction to the place deduced from them. It may be mentioned that the calculations of the transit in the Nautical Almanac, the Connaissance des Temps, and the Berliner Astronomisches Jahrbuch, depend upon Leverrier's tables. For the diameter of the planet we adopt that found by Prof. Auwers from heliometric measures in Egypt during the last transit, combining it with the diameler of the sun, inferred by Leverrier from his discussion of the transits of Mercury.

Direct calculations for Greenwich, Edinburgh, and Dublin give with the elements so obtained the following Greenwich mean times of the first external contact, and the respective angles from the sun's vertex for direct image :-

$$
\begin{aligned}
& \begin{array}{cccccccccc}
\text { Greenwich } & \ldots & \ldots & \text { h. } & \text { m. } & \text { s. } & & & \text { o } & \multicolumn{2}{c}{\cdot \mathbf{2}} & \ldots & \ldots & \text { I } 26 & 59 \cdot 4
\end{array}
\end{aligned}
$$

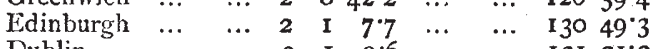

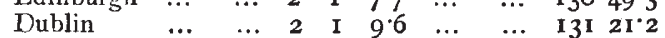

For a limited area like that of these islands we may apply to these times and angles, the method of distribution of predictions given by Littrow, and subsequently by Woolhouse. Putting the latitude of any place within the above area $=50^{\circ}+\mathrm{L}$, and its longitude in minutes of time $=\mathrm{M},+$ if east of Greenwich, - if west, we get the following equations:-

G.M.T. of first ex-

ternal contact $\ldots\}=2 \mathrm{~h} .0 .62 \mathrm{~m} .+[8 \cdot 7453] \mathrm{L}-[8 \cdot 1402] \mathrm{M}$. Angle from sun's ver- $>$

tex, direct image... $\}=126^{\circ} \cdot 3+\left[9^{\circ} 669\right] \mathrm{L}-\left[9^{\cdot 136}\right] \mathrm{M}$.

The quantities within the square brackets are logarithms, but of course if preferred the factors for $L$ and $M$ may be expressed as numbers. As an example of the application of these formulæ, suppose the time of first contact and the corresponding angle are required for Norwich, the position of which place may be taken in latitude $+52^{\circ} 38^{\prime}$, longitude $1^{\circ} 18^{\prime}$ or $+5 \mathrm{~m}$. 12s., we have then

$$
\begin{aligned}
& \mathrm{L}=+2^{\circ} .633 \mathrm{M}=+5^{\circ} .20 \mathrm{~m} \text {. }
\end{aligned}
$$

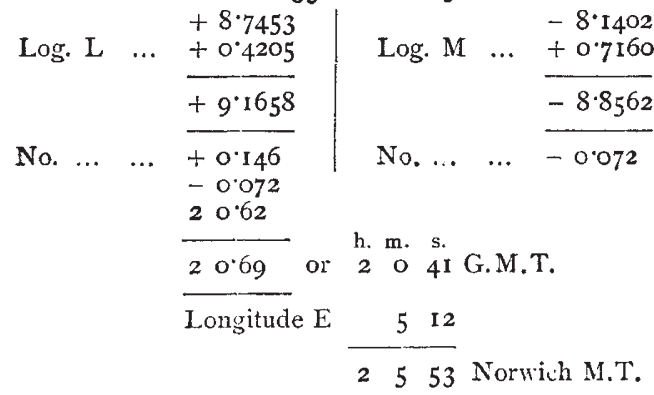

For the angle-

$$
\begin{aligned}
& +9.669-9^{\circ} \cdot 136 \mid+1 \cdot 23 \\
& \begin{array}{l|l|l}
\text { Log. L + 0.42I } & \text { Log. M + 0.716 } & -0.71
\end{array} \\
& \begin{array}{l|l|l}
\hline+10.090 & -9.852 & \frac{126.3}{126.8 \ldots} \text { angle from vertex. }
\end{array}
\end{aligned}
$$

So that according to the calculation the limb of the planet comes into first contact with that of the sun at $53^{\circ}$ from his lowermost point towards the left, as we view the phenomenon with the naked eye. It will be remarked that there is less than a half minute difference in absolute time between Greenwich and Dublin, and considering the possibility of error of many seconds in any prediction that can be made for geometrical contact and the difficulty of always determining what is geometrical contact in the observations, our formula for time of first contact is more than a sufficient one.

For first internal contact, it may be assumed that $2 \mathrm{I}$ minutes have to be added to the time of external contact at any place in these islands; while for the angle from N. point of first external contact may be taken in all cases $147^{\circ}$.

In the national ephemerides the times of the contacts are given for a particular meridian as they would be noted at the centre of the earth, and formulæ are appended to reduce these geocentric times to any point upon the earth's surface. It is obvious that where, as in a transit of Venus, predictions are required for such widely distant stations, this method possesses the greatest convenience.

\section{NOTES}

THE following are the Lecture arrangements at the Royal Institu. tion for the ensuing Session:-The Christmas Lectures will be given hy Prof. Tyndall, on Light and the Eye. Before Easter-Prof. W. C. Williamson on the Primeval Ancestors of Existing Vegetation, and their Bearing upon the Doctrine of Evolution; Prof. R. S. Ball, four lectures on the Supreme Discoveries in Astronomy; Prof. Dewar, nine lectures on the Spectroscope and its Applications; Mr. R. Bosworth Smith, four lectures on Episodes in the Life of Lord Lawrence; Dr. W. H. Stone, three lectures on Singing, Speaking, and Stammering; Mr. H. H. Statham, two lectures on Music as a Form of Artistic Expression. After Easter-Courses will be given by Professors Tyndall, McKendrick, A. Geikie, and Turner (of St. Petersburg). The Friday Evening Discourses will probably be given, among others, by Mr. R. B. Smith, Dr. G. J. Romanes, Sir W. Thomson, Mr. M. D. Conway, Prof. W. C. Williamson, Mr. W. H. Pollock, and Prof. Tyndall.

A committee, consisting of the Right Hon. J. T. Ball, LL.D., D.C.L., the Very Rev. W. Reeves, D.D., Dean of Armagh, J. L. E. Dreyer, Ph.D., Astronomer of Armagh Observatory, has been appointed by the Governors of the Armagh Obsirvatory to raise a fund for the purpose of erecting a memorial instrument in the observatory at Armagh, where the late Rev. Dr. Robinson spent fifty-eight years, engaged in those scientific investigations with which his name will be for ever associated. The Committee addresses its appeal not only to the inhabitants of Ulster, or of Dublin, but to Robinson's friends and adwirers all over the United Kingdom. The services rendered to astronomy by Dr. Robinson are well known, and doubtless many of our readers will be glad to aid in paying a tribute to his memory. It is proposed that the memorial take the form of an equatoreal refractor, say of eight or nine inches aperture, which could be had for about $500 \%$, and could find room in one of the existing domes at Armagh. With such an instrument, much valuable and interesting work could be done. Subscriptions should be sent to Dr. J. L. E. Dreyer, Observatory, Armagh. 